\title{
Modification of Butadiene-Acrylonitrile Rubber/Poly(Vinyl Chloride) Blend Using Natural Rubber, Styrene-Butadiene Rubber, and Polybutadiene Rubber
}

\author{
K. E. GEORGE, RANI JOSEPH, D. JOSEPH FRANCIS, and \\ K. T. THOMAS* \\ Dept. of Polymer Science \& Rubber Technology \\ Cochin University of Science and Technology \\ Cochin 682 022, India
}

\begin{abstract}
Natural rubber, styrene-butadiene rubber, and polybutadiene rubber were used to replace part of the butadieneacrylonitrile rubber in a 70/30 butadiene-acrylonitrile rubber/poly(vinyl chloride) blend. Such replacement up to $15 \%$ of the total weight of the blend improved the mechanical properties, while decreasing the cost of the blend. Styrenebutadiene rubber could replace butadiene-acrylonitrile rubber up to $30 \%$ of the total weight of the blend without deterioration in the mechanical properties.
\end{abstract}

\section{INTRODUCTION}

B lending of polymers for property improvement or for economic advantage has gained considerable importance. Poly(vinyl chloride) (PVC) homopolymer is a stiff and brittle material. For many applications, therefore, it is useful to blend PVC with other polymers or copolymers in order to improve its properties. One of the most suitable modifying additives is butadiene-acrylonitrile rubber (NBR) (1). NBR acts as a permanent plasticizer for PVC in applications such as wire and cable insulation, food containers, pond liners used for oil containment, etc. On the other hand, PVC improves ozone, thermal aging, and chemical resistance of NBR in applications such as fuel hose covers, gaskets, conveyor belt convers, printing roll covers, etc. (2). Because of good NBR/PVC compatibility, their blends can be prepared in any proportion with predictable properties (3).

Common rubbers such as natural rubber (NR), styrene-butadiene rubber (SBR), and polybutadiene rubber (BR) are not likely to be compatible with either NBR or PVC (4) and, hence, the effect of modifying an NBR/PVC blend by any of them cannot be easily predicted (3). In this study, NBR up to $30 \%$ of the total weight of a 70/30 NBR/PVC blend is replaced by NR, SBR, and BR while the amount of PVC stays constant, and the properties of the vulcanizates are compared. Magnesium oxide (MgO) and zinc oxide $(\mathrm{ZnO})$ combination in presence of stearic acid recently has been shown to be an efficient

- On leave from Rubber Research Institute of India, Kottayam 686 009, India. stabilizer for PVC, particularly in PVC-based blends (5-7). Hence, this stabilizer was used in this study.

\section{EXPERIMENTAL}

\section{Materials}

The polymers used in this study were:

PVC (powder; suspension polymer; $K$ value $=65$ )

NBR (33\% acrylonitrile; Mooney viscosity, $\mathrm{ML}(1+4)$ at $\left.100^{\circ} \mathrm{C}, 40.9\right)$

NR $\left(\bar{M}_{w}=7.70 \times 10^{5}\right.$; ISNR 5 (Rubber Research Institute of India); Mooney viscosity, ML $(1+4)$ at $\left.100^{\circ} \mathrm{C}, 85.3\right)$

SBR (23.5\% styrene; Mooney viscosity, ML $(1+4)$ at $\left.100^{\circ} \mathrm{C}, 49.2\right)$

BR $(97 \% 1,4$ (cis); Mooney viscosity, ML $(1+4)$ at $\left.100^{\circ} \mathrm{C}, 48.0\right)$.

\section{Studies on a Brabender Plasticorder}

An attempt was made to determine the relative effect of substituting part of NBR in a 70/ 30 NBR/PVC blend with NR, SBR, and BR on a Brabender Plasticorder Model PL3S (rotor speed: $30 \mathrm{rpm}$, sensitivity $0-5000$ metergrams, mixer temperature $160^{\circ} \mathrm{C}$ ). The total weight of polymers taken for each run was $40 \mathrm{~g}$. In addition to the polymers, 4 parts of MgO per hundred parts of PVC resin (phr), $4 \mathrm{phr} \mathrm{ZnO}$. and $3 \mathrm{phr}$ stearic acid were added as stabilizer for PVC. Initially, the mixing characteristics of an NBR/PVC blend that contained $70 \%$ NBR (of the total polymer weight) was studied. NBR was added initially and homogenized for $2 \mathrm{~min}$, then 
PVC together with its stabiliser was added. The blending was contained for $10 \mathrm{~min}$ after the torque passed the maximum value.

The blending characteristics of the terpolymer blends, made by replacing NBR partly $(30 \%$ of the total weight of polymers) by NR, SBR, and $\mathrm{BR}$, were investigated next. NR, SBR, or BR was added initially and homogenized for $2 \mathrm{~min}$, then NBR was added and mixed for another $2 \mathrm{~min}$. Next PVC along with its stabilizer was added. After the torque passed the maximum value, the blending was continued for another $10 \mathrm{~min}$ as before. The Brabender torque curves along with the amounts of polymers added are shown in Fig. 1.

\section{Determination of Mechanical Properties}

For measuring the mechanical properties, an NBR/PVC blend containing $70 \%$ NBR (of the total polymer weight) was also chosen as the standard. The effect of modifying this blend by NR, SBR, and BR on the mechanical properties was determined by replacing parts of NBR $(15 \%$ and $30 \%$ of the total polymer weight) by each of these rubbers and then measuring the change in the properties. However, the polymers were not melt mixed for preparing the test samples, since the Brabender studies have shown that melt mixing leads to some degradations particularly in the NR, SBR, and BR phases. Hence, NBR/PVC blend alone was made on a Brabender Plasticorder initially at the optimum temperature (7), together with the stabilizer for PVC (4 phr $\mathrm{MgO}, 4 \mathrm{phr} \mathrm{ZnO}$, and $3 \mathrm{phr}$ stearic acid). The terpolymer blends were then made by adding NR, SBR, or BR to the NBR/PVC blend on a warm laboratory mixing mill. The vulcanizing agents for the rubber(s) were also added on the mill. The formulations employed for the preparation of the various compounds are shown in Table 1.

The cure characteristics of the compounds were determined at $150^{\circ} \mathrm{C}$ on a Monsanto Rheometer Model R 100 (Table 2). Test samples were vulcanized up to the respective cure time at $150^{\circ} \mathrm{C}$.

The tensile properties were determined on a Zwick Universal Testing Machine as per ASTM D 412 (1980). Tear strength of the samples was determined as per ASTM D 624 (1981). The

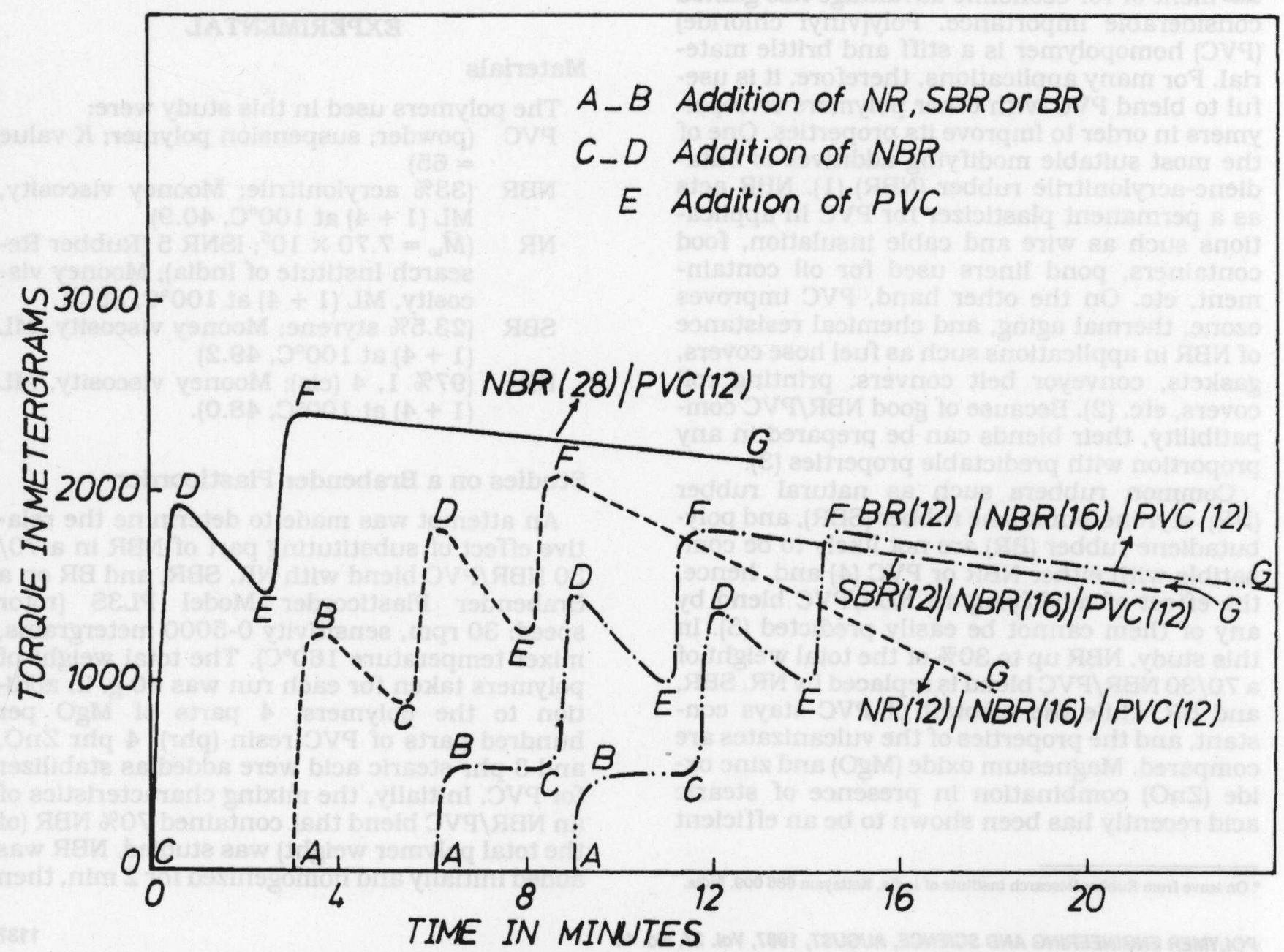

Fig. 1. Brabender torque curves of the polymer blends. Weight in grams of each polymer added is shown within parentheses. Times marked in the abscissa refers only to the torque curve of the NBR/PVC blend. For the others, zero starts from 
hardness of the samples was measured and expressed in Shore A units. The swelling characteristics were determined in chloroform, toluene, and an aromatic oil as per ASTM 471 (1983). The properties of the blends are shown in Table 2.

\section{RESULTS AND DISCUSSION}

The Brabender torque curve for the NBR/PVC blend in Fig. 1 may be explained as follows: NBR is added in the region C to D and, hence, the torque rises. Once the addition is complete, the rubber homogenizes and the torque begins to decrease at $\mathrm{D}$ because of mechanochemical degradation. PVC is added at $\mathrm{E}$ and because of its melting, the torque rises to F. Again, there

Table 1. Formulations Used for Preparation of Test Samples.

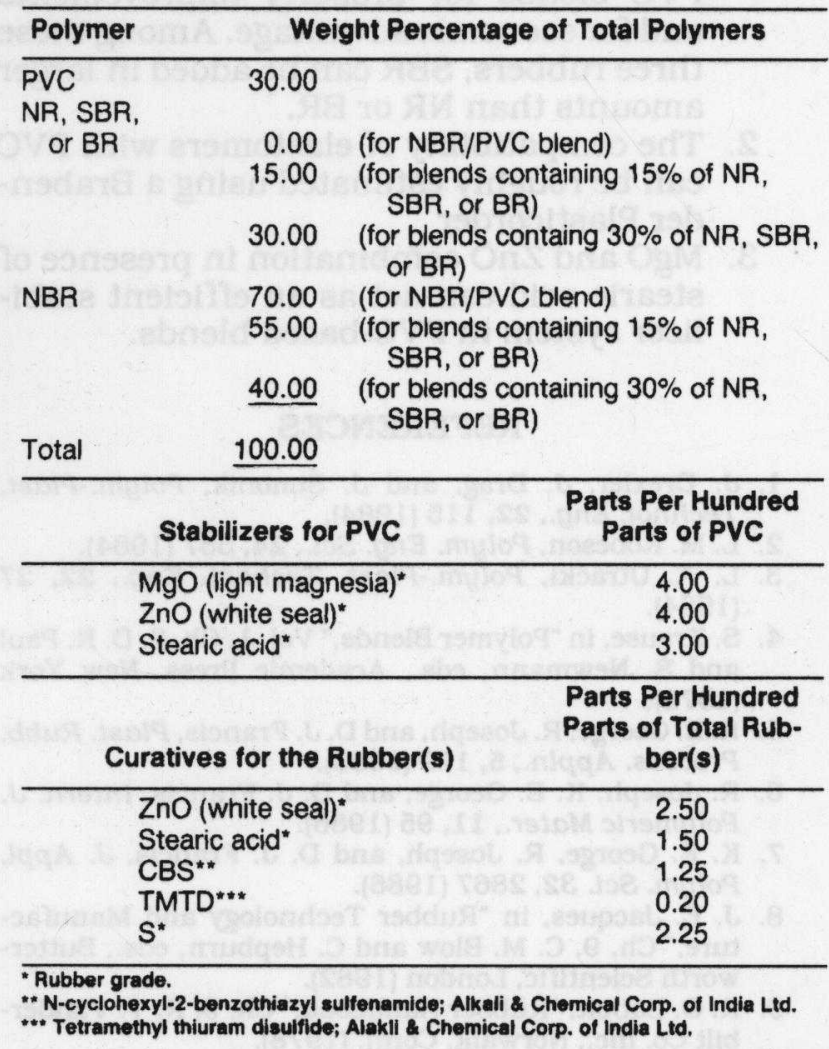

is a tendency for the torque to drop slightly up to G. However, the rate of decrease in torque from $F$ to $G$ is much less than that from $D$ to $E$ indicating that PVC offers good protection to NBR against the degradation, obviously because of the compatible nature of the polymers. There is also no visual evidence for any degradation of the blend during blending.

A comparison of the four torque curves in Fig. 1 indicates that maximum torque rise from $\mathrm{E}$ to $\mathrm{F}$ occurs in the case of the NBR/PVC blend. This shows that even though the same amount of PVC (12 g) was added in each case, the maximum amount melted in this case showing again the good compatibility of NBR and PVC. These observations might indicate that the relative compatibility of PVC with the rubber(s) may be approximately estimated from the following factors:

1. Amount of PVC melting (torque rise from $\mathrm{E}$ to $\mathrm{F}$ )

2. Amount of protection offered by the PVC phase against the degradation of the rubber(s) (rate of decrease in torque from $\mathrm{F}$ to $\mathrm{G}$ compared with the rate of decrease from $\mathrm{D}$ to $\mathrm{E}$ and visual examination of the blend for any color development during the test run on the plasticorder). The former (1) is likely to give more useful information if similar tests are conducted at a lower temperature, and the latter (2) is if the tests are conducted at a higher temperature.

In the case of NR/NBR/PVC blend, the addition of a mere $12 \mathrm{~g}$ of NR initially produces a fast rate of degradation, as seen from the torque curve from $B$ to $C$. This is due to the high molecular weight of NR. When NBR is also added, the net rate of decrease in torque from $D$ to $E$ increases because of the larger amount of rubber. With the addition of PVC, the torque rises from $E$ to $F$. However, this difference in torque is less than that observed in the case of the NBR/PVC blend. Further, the protection offered by PVC against the degradation of the rubbers seems low, judging from the rate of decrease in torque from $\mathrm{F}$ to $\mathrm{G}$, indicating poor compatibility. The degradation of the blend in-

Table 2. Properties of Blends.

\begin{tabular}{|c|c|c|c|c|c|c|c|}
\hline \multirow{2}{*}{\multicolumn{2}{|c|}{ NBR/PVC }} & \multicolumn{2}{|c|}{ NR/NBR/PVC } & \multicolumn{2}{|c|}{ SBR/NBR/PVC } & \multicolumn{2}{|c|}{ BR/NBR/PVC } \\
\hline & & $15 \%$ NR & $30 \%$ NR & $15 \%$ SBR & $30 \%$ SBR & $15 \% \mathrm{BR}$ & $30 \%$ BR \\
\hline $\begin{array}{l}\text { Tensile strength }(\mathrm{MPa}) \\
\text { Elongation at break }(\%) \\
\text { Tear strength }(\mathrm{N} / \mathrm{mm}) \\
\text { Hardness (Shore } \mathrm{A}) \\
\text { Swelling index: } \\
\text { (Equilibrium wt - original wt) } \times 100 \\
\end{array}$ & $\begin{array}{c}10.3 \\
513 \\
45.90 \\
58.0\end{array}$ & $\begin{array}{l}13.0 \\
550 \\
55.75 \\
57.0\end{array}$ & $\begin{array}{l}8.4 \\
350 \\
32.82 \\
56.0\end{array}$ & $\begin{array}{c}11.0 \\
488 \\
42.72 \\
62.0\end{array}$ & $\begin{array}{c}11.5 \\
510 \\
41.0 \\
62.0\end{array}$ & $\begin{array}{l}12.3 \\
515 \\
42.40 \\
60.0\end{array}$ & $\begin{array}{c}5.6 \\
230 \\
28.9 \\
62.0\end{array}$ \\
\hline $\begin{array}{l}\text { original weight } \\
\text { (a) chloroform } \\
\text { (b) toluene } \\
\text { (c) aromatic oil } \\
\text { Cure Characteristics: }\end{array}$ & $\begin{array}{r}732.03 \\
148.00 \\
1.39\end{array}$ & $\begin{array}{r}667.57 \\
165.40 \\
4.44\end{array}$ & $\begin{array}{r}639.10 \\
190.80 \\
9.28\end{array}$ & $\begin{array}{r}710.67 \\
155.50 \\
7.19\end{array}$ & $\begin{array}{l}664.6 \\
164.80 \\
13.40\end{array}$ & $\begin{array}{r}617.86 \\
162.40 \\
5.34\end{array}$ & $\begin{array}{r}596.18 \\
172.50 \\
9.33\end{array}$ \\
\hline $\begin{array}{l}\text { (a) scorch time (mts.) } \\
\text { (b) cure time (mts.) } \\
\text { (c) Reversion (no. of units dropped }\end{array}$ & $\begin{array}{r}6.50 \\
12.00 \\
\text { Nil }\end{array}$ & $\begin{array}{l}5.50 \\
8.50 \\
\text { Nil }\end{array}$ & $\begin{array}{l}4.50 \\
7.50\end{array}$ & $\begin{array}{r}8.00 \\
12.00 \\
\text { Nil }\end{array}$ & $\begin{array}{r}7.00 \\
10.50 \\
\text { Nil }\end{array}$ & $\begin{array}{r}6.50 \\
10.00 \\
\text { Nil }\end{array}$ & $\begin{array}{l}5.00 \\
8.00\end{array}$ \\
\hline in $5 \mathrm{mts}$.) & NoII & IVII & 1.0 & NIII & NII & Nii & Nil \\
\hline
\end{tabular}


K. E. George, R. Joseph, D. J. Francis, and K. T. Thomas

side the plasticorder also could be observed visually from the color development.

In the case of SBR/NBR/PVC blend, the initial rate of decrease in torque from $B$ to $C$ is very little because of the low molecular weight of SBR. However, with the addition of NBR, the degradation becomes obvious (D to $\mathrm{E}$ ) because of the greater amount of rubber. But with the addition of PVC, the rate of degradation is reduced ( $F$ to $G$ ) indicating better adhesion between the phases in this case than in the NR/ NBR/PVC blend. However, the rise in torque from $E$ to $F$ is similar to that of NR, and there is visual evidence for slight color development indicating lesser compatibility than in the blend of NBR and PVC alone. The behavior of the BR/ NBR/PVC blend is similar to that of the SBR/ NBR/PVC blend, but indicates lower level of blending.

An examination of the tensile properties of the blends shows that when the NBR/PVC blend is modified with NR, SBR, or BR at $15 \%$ level, the properties are improved. It may be inferred that at this level the incompatibility of the polymers does not seriously affect the mechanical properties. As expected, the NR/NBR/PVC blend shows the maximum tensile strength and elongation $(8-10)$. However, when NR or BR is present at $30 \%$ level, the tensile properties deteriorated severely, obviously indicating the incompatible nature of the polymers. This shows that the optimum amount of NR or BR that can be added to NBR/PVC blends is much less than this quantity. SBR, which has similar tensile properties as NBR, exhibits more or less steady behavior even when added at 30\% level. This again shows that SBR blends better with NBR/ PVC blends than NR or BR and that SBR could be added to the blend in larger amounts than NR or BR. The tear strength of the blends also shows a similar trend as the tensile properties. SBR and BR blends show a higher hardness than the NR blend, as expected $(8-10)$. The swelling index values show that the swelling rates of NBR/PVC blends in polar solvents like chloroform can be reduced by the addition of
NR, SBR, or BR. Considering the enormous swelling rates of NBR in polar solvents (11), this could be an advantage in some applications. However, there is some increase in the swelling rates of the NBR/PVC blends in nonpolar solvents and oils with the addition of NR, SBR, or $\mathrm{BR}$ as shown by the swelling index values of the blends in toluene and an aromatic oil.

\section{CONCLUSIONS}

The study helps to draw the following conclusions:

1. NR, SBR, or BR can replace NBR in NBR/ PVC blends for property improvements and for economic advantage. Among these three rubbers, SBR can be added in larger amounts than NR or BR.

2. The compatibility of elastomers with PVC can be roughly estimated using a Brabender Plasticorder

3. $\mathrm{MgO}$ and $\mathrm{ZnO}$ combination in presence of stearic acid can act as an efficient stabilizer system in PVC-based blends.

\section{REFERENCES}

1. J. Drexler, J. Drag, and J. Simonik, Polym.-Plast. Technol. Eng., 22, 115 (1984).

2. L. M. Robeson, Polym. Eng. Sci., 24, 587 (1984).

3. L. A. Utracki, Polym.-Plast. Technol. Eng., 22, 27 (1984).

4. S. Krause, in "Polymer Blends," Vol. 1, Ch. 2, D. R. Paul and S. Newmann, eds., Academic Press, New York (1978).

5. K. E. George, R. Joseph, and D. J. Francis, Plast. Rubb. Process. Appln., 5, 179 (1985).

6. R. Joseph, K. E. George, and D. J. Francis, Intern. J. Polymertc Mater., 11, 95 (1986).

7. K. E. George, R. Joseph, and D. J. Francis, J. Appl. Polym. Sct. 32, 2867 (1986).

8. J. E. Jacques, in "Rubber Technology and Manufacture," Ch. 9, C. M. Blow and C. Hepburn, eds., Butterworth Scientific, London (1982).

9. R. O. Babbit, "Rubber Handbook," Ch. 9, R. T. Vanderbilt Co. Inc., Norwalk, Conn. (1978).

10. F. W. Billmeyer, "Textbook of Polymer Science," Ch. 19. John Wiley \& Sons, New York (1984).

11. H. H. Bertram, in "Developments in Rubber Technology-2," Ch. 3, A. Whelan and K. S. Lee, eds., Applied Science Publishers Ltd, London (1981). 